\title{
Are olive pomace powders a safe source of bioactives and nutrients?
}

\author{
Tânia Bragança Ribeiro, ${ }^{\mathrm{a}, \mathrm{b}}$ Ana Oliveira, ${ }^{\mathrm{a}}$ Marta Coelho, ${ }^{\mathrm{a}}$ Mariana Veiga, ${ }^{\mathrm{a}}$ \\ Eduardo M Costa, ${ }^{a}$ Sara Silva, ${ }^{a}$ João Nunes, ${ }^{b}$ António A Vicente ${ }^{c}$ and \\ Manuela Pintado ${ }^{a^{*}} \odot$
}

\begin{abstract}
BACKGROUND: The olive oil industry generates significant amounts of semi-solid wastes, namely olive pomace. Olive pomace is a by-product rich in high-value compounds (e.g. dietary fibre, unsaturated fatty acids, polyphenols) widely explored to obtain new food ingredients. However, conventional extraction methods frequently use organic solvents, while novel eco-friendly techniques have high operational costs. The development of powdered products without any extraction step has been proposed as a more feasible and sustainable approach.

RESULTS: The present study fractionated and valorized the liquid and pulp fraction of olive pomace obtaining two stable and safe powdered ingredients, namely a liquid-enriched powder (LOPP) and a pulp-enriched powder (POPP). These powders were characterized chemically, and their bioactivity was assessed. LOPP exhibited a significant amount of mannitol $\left(141 \mathbf{~ g ~ k g}^{-1}\right)$, potassium $\left(54 \mathrm{~g} \mathrm{~kg}^{-1}\right)$ and hydroxytyrosol derivatives $\left(5 \mathrm{mg} \mathrm{g}^{-1}\right)$. POPP exhibited a high amount of dietary fibre $\left(620 \mathrm{~g} \mathrm{~kg}^{-1}\right)$ associated with a significant amount of bound phenolics (7.41 $\mathrm{mg} \mathrm{GAE}^{-1}$ fibre DW) with substantial antioxidant activity. POPP also contained an unsaturated fatty acid composition similar to that of olive oil ( $76 \%$ of total fatty acids) and showed potential as a reasonable source of protein (12\%). Their functional properties (solubility, water-holding and oil-holding capacity), antioxidant capacity and antimicrobial activity were also assessed, and their biological safety was verified.
\end{abstract}

CONCLUSIONS: The development of olive pomace powders for application in the food industry could be a suitable strategy to add value to olive pomace and obtain safe multifunctional ingredients with higher health-promoting effects than dietary fibre and polyphenols.

() 2020 Society of Chemical Industry

Supporting information may be found in the online version of this article.

Keywords: olive pomace; powder; hydroxytyrosol; antioxidant dietary fibre; functional ingredient

\section{INTRODUCTION}

The large quantities of food by-products and wastes produced every year are responsible for significant resource depletion and environmental problems. In this sense, the food industry has been driven to achieve 'zero wastes food systems' in line with the recent European Union (EU) Circular Economy Action Plan ${ }^{1}$ and European Bioeconomy Strategy. ${ }^{2}$

Currently, olive oil production is one of the most polluting agrofood industries, ${ }^{3}$ producing the commonly known olive pomace (OP). This semi-solid waste is obtained from the two-phase system and represents the highest waste-management challenge of the sector. ${ }^{4} \mathrm{OP}$ is difficult to treat because of its high water and organic compounds content. ${ }^{5}$ However, OP contains also a substantial amount of compounds such as dietary fibre (DF), ${ }^{6}$ unsaturated fatty acids (UFAs), ${ }^{7}$ minerals ${ }^{8}$ and phenolic compounds. ${ }^{5}$ Taking into account its richness in high-value compounds for food formulation, OP should be considered a by-product. The term 'food by-products' was introduced by the EU Commission to advise that 'food wastes' represent a loss of valuable biomass and nutrients which could be recovered to develop new co-products with market value. ${ }^{2,9,10}$
Currently, EU legislation and plans promote the search for new end-uses for food by-products. ${ }^{2,9,10}$ In consequence, the development of new food ingredients from by-products has been emerging, not only as an attempt to achieve more sustainable food production chains but also attending to the increasing demand of consumers for healthier and more functional foods ${ }^{11-14}$

* Correspondence to: M Pintado, Universidade Católica Portuguesa, Escola Superior de Biotecnologia, CBQF - Centro de Biotecnologia e Química Fina, Laboratório Associado, Rua de Diogo Botelho 1327, 4169-005 Porto, Portugal. E-mail: mpintado@porto.ucp.pt

a CBQF - Centro de Biotecnologia e Química Fina, Laboratório Associado, Universidade Católica Portuguesa, Escola Superior de Biotecnologia, Porto, Portugal

b Association BLC3, Technology and Innovation Campus, Centre Bio R\&D Unit, Oliveira do Hospital, Portugal

c CEB - Centre of Biological Engineering, Universidade do Minho, Campus de Gualtar, Braga, Portugal 
Furthermore, this valorization strategy could generate economic gains for the food industry and reduce the resource depletion and environmental problems from waste mismanagement. ${ }^{13,14}$

In the same framework, the development of powdered ingredients without any extraction has been proposed as a more feasible and low-environmental-impact approach than the traditional and emerging technologies that involve the use of organic solvents or have higher operational costs, respectively. ${ }^{15}$ Besides that, powdered products have the advantage of retaining various functional compounds, namely fatty acids, polysaccharides, minerals and phenolics, together under synergic interaction giving these products multifunctional properties. ${ }^{16}$

The OP solid fraction stood out as a potential raw material for developing new antioxidant dietary fibre (ADF) powders in our previous work. Furthermore, $1 \mathrm{~g}$ of OP liquid fraction has been shown to retain more than $5 \mathrm{mg}$ of hydroxytyrosol and its derivatives which according to the health claim approved by the EFSA, if consumed daily would 'protect LDL particles from oxidative damage'. ${ }^{17}$ However, until now studies substantiating the antioxidant capacity of phenolics present in olive oil have been limited, and no data are available for other food matrices. ${ }^{17}$ Nevertheless, numerous other studies have shown the potential of hydroxytyrosol for preventing certain diseases (e.g. cancer, digestive disorders $)^{18}$ and as a food preservative against fat oxidation and microbial contamination. ${ }^{19-21}$ Other compounds such as simple phenolics (caffeic and $p$-coumaric acids) and polyphenols (luteolin) were identified in OP liquid fraction, but dihydroxyphenolics such as hydroxytyrosol and tyrosol were the most significant.

After the validation of the potential of OP liquid and solid fractions as food ingredients, the next step was to develop new food powdered ingredients from OP. To guarantee the economic feasibility, stability and safety of such OP powders, some procedures were undertaken, including: (i) selection of a more cost-effective drying process taking into consideration the stability of bioactive compounds and microbiological safety ${ }^{22,23}$; (ii) addition of food additives to improve stability ${ }^{24}$; and (iii) removal of physical hazards such as small pieces of stones. ${ }^{25}$

OP powders exhibit a reasonable potential as a source of various nutrients and bioactive compounds ${ }^{5-8}$ with potential complementary/synergetic benefits in terms of health benefits ${ }^{26}$ and technological properties (antioxidant, antimicrobial and aroma/ taste enhancement). The production and characterization of OP powders have been scarcely studied. ${ }^{26-29}$ Nonetheless, their potential application in the food industry as safe and multi-source compounds has been even more undervalued. ${ }^{26}$ The identification and evaluation of the antioxidants present in DF from OP have been barely studied, ${ }^{26,30}$ and the potential toxic character of OP phenolics has been neglected. ${ }^{31}$ Thus, a more systematic and comprehensive evaluation of their benefits and possible adverse effects is required, e.g. a study concerning genotoxicity and mutagenicity, that have been scarcely investigated.

So, in the work presented here, two OP powders from the liquid and solid fractions were proposed as new sustainable coproducts with food market value. To understand the potential of these powders and guarantee their safe application in the food industry, an evaluation of their nutritional composition, bioactive composition (including DF), bioactivity (antioxidant and antimicrobial), functional properties and safety issues (genotoxicity and cytotoxicity) was conducted. The cytotoxicity and mutagenicity of OP powders were analysed for the first time.

\section{MATERIALS AND METHODS}

\section{Reagents}

Mannitol, DPPH (2,2-diphenyl-1-picrylhydrazyl), ABTS diammonium salt (2, 2-azinobis-3-ethylbenzothiazoline-6-sulfonic acid), 2,2'-azobis(2-methylpropionamidine) dihydrochloride (AAPH), fluorescein, methanol, potassium sorbate, amino acid pure standards and sodium carbonate were purchased from SigmaAldrich (Sintra, Portugal). Folin-Ciocalteu reagent and potassium persulfate were purchased from Merck (Algés, Portugal). Muller Hinton broth (MHB) was obtained from Biokar Diagnostics (Beauvais, France). Standards of Trolox, gallic acid, $p$-coumaric acid, vanillin, protocatechuic acid, caffeic acid and quercetin were obtained from Sigma-Aldrich (Sintra, Portugal). Hydroxytyrosol, tyrosol and luteolin were purchased from Extrasynthese (Lyon, France).

\section{Preparation of OP powders}

OP was collected in an olive mill with a two-phase extraction system from Oliveira do Hospital, Portugal (mainly composed of the olive cultivar Galega vulgar). Various samples of OP were collected shortly after being separated from olive oil and mixed. These homogeneous samples were immediately packed in polyethene flasks and frozen at $-80{ }^{\circ} \mathrm{C}$, where they were kept until use.

OP was fractionated by centrifugation (10 $000 \times g$ for $10 \mathrm{~min})$. The liquid fraction was freeze-dried (Telstar Lyo Quest HT 40) with $2 \%$ mannitol (as a cryoprotectant to prevent aggregation) and designated liquid-enriched OP powder (LOPP). The solid fraction was dried at $90{ }^{\circ} \mathrm{C}$ until levels of water activity $\left(a_{\mathrm{w}}\right)$ were below 0.4 (on average $90 \mathrm{~min}$ ), in order to obtain a stable product. ${ }^{22}$ Previous drying experiments were performed $\left(50,70\right.$ and $\left.90^{\circ} \mathrm{C}\right)$ and the highest temperature presented the best results regarding the total phenolic compounds (TPC) and antioxidant activity (AOX), in line with previous studies. ${ }^{22,23}$ The dried solid fraction was milled using a coffee grinder and sieved to isolate all the pieces of stones and to obtain a potentially food-grade ingredient free of physical hazards. ${ }^{25}$ A particle size distribution study using a sieve shaker with a series of sieves (mesh nos. 10, 18, 30, 40, 60, 100 and 200) was executed to guarantee the elimination of all the pieces of stones (supporting information 1). The fractions retained until mesh 40 (fractions with pieces of stones) were removed, and the other fractions were combined to afford pulp-enriched OP powder (POPP). POPP represents $51.55 \%$ dry weight (DW) of the total solid fraction, and its particle size ranged between 75 and $400 \mu \mathrm{m}$. The average mesh most representative was the 100 mesh (75-150 $\mu \mathrm{m})$. The relatively large particle size was chosen to maintain the hydration characteristics and the microtexture of the fibre. $^{32}$

\section{Chemical composition of OP powders Proximate composition}

All procedures followed the recommendations of the Official Methods of Analysis. ${ }^{33}$ The crude protein content was determined using the Kjeldahl method (conversion factor: 6.25). The lipid content was obtained according to method 920.39. The crude ash content was estimated by incineration (method 942.05). The moisture content was determined following method 934.06. All measurements were done in triplicate and expressed as grams per $100 \mathrm{~g} \mathrm{DW}$. 
Analysis of chemical components of ash, protein, lipids and carbohydrates

Mineral concentration was determined following the methodology of Amorim et al. ${ }^{35}$ using an optical emission spectrometer (Optima 7000 DV $^{\mathrm{TM}}$ ICP-OES, Dual View, PerkinElmer Life and Analytical Sciences, Shelton, CT, USA) with a radial configuration. The free sugar and organic acid content were obtained ${ }^{34}$ and determined using Beckman Coulter System Gold HPLC (Knauer, Berlin, Germany) coupled to RI and UV detectors using an Aminex 37-H column (Bio-Rad, Berkeley, USA) at $55^{\circ} \mathrm{C}$ and $35 \mathrm{mmol} \mathrm{L}^{-1} \mathrm{H}_{2} \mathrm{SO}_{4}$ as mobile phase (flow rate: $0.5 \mathrm{~mL} \mathrm{~min}^{-1}$ ). The quantification was achieved using standard calibration curves $\left(0.2-2.0 \mathrm{mg} \mathrm{mL}^{-1}\right)$. Total amino acid content of each powder was determined using pre-column derivatization with orthophthalaldehyde (OPA) methodology ${ }^{35}$ and quantified using a calibration curve built with amino acid pure standards. The profile of fatty acids was obtained and analysed following the methodology of Pimentel et al. ${ }^{36}$ with some modifications regarding the internal standard used (glyceryl tritridecanoine, TGC13) and the derivatization process (methanol and sodium methoxide were added to $50 \mathrm{mg}$ of sample in amounts of $2.26 \mathrm{~mL}$ and $240 \mu \mathrm{L}$, respectively). All measurements were done in triplicate and expressed as grams per $100 \mathrm{~g} \mathrm{DW}$.

\section{Bioactive phytochemicals}

Total phenolic compound extraction and quantification: free and bound phenolics

The free phenolic compounds (FPC) were obtained using methanol as solvent (1:10, $1 \mathrm{~h}$ of agitation on orbital shaker $200 \mathrm{rpm}$, two successive extractions). The residue obtained after FPC extraction was hydrolysed with $20 \mathrm{~mL}$ of $4 \mathrm{~mol} \mathrm{~L}^{-1} \mathrm{NaOH}$ at room temperature. ${ }^{37}$ The collected fraction of phenolic compounds was designated as bound phenolic compounds (BPC). The total phenolic content (TPC) of FPC and BPC extracts was determined according to the Folin-Ciocalteu method. ${ }^{38}$ Results were expressed as milligrams gallic acid equivalents (GAE) per $100 \mathrm{~g} \mathrm{DW}$.

\section{Determination of DF composition}

TDF content was estimated using the enzyme-gravimetric method, according to AOAC method 991.43 (1990), with slight modifications according to Deng et al. ${ }^{34}$ The results were expressed as grams of TDF, IDF and SDF per $100 \mathrm{~g} \mathrm{DW}$. The IDF and SDF profiles were assessed in agreement with the methodology of Deng et al. ${ }^{34}$

The phenolic compounds were released from IDF and SDF fractions using the same hydrolysis process as described in the previous section. This methodology is in agreement with the procedure applied for other food matrices such as whole-grain cereals $^{39}$ to release BPC from IDF and SDF. The BPC extracts obtained from IDF and SDF were designated as IDF-BPC and SDF$B P C$, respectively. These extracts were used to measure TPC (as described above), AOX (methodology described in the following section) and identification of phenolic compounds by LC-ESIUHR-QqTOF-MS (methodology described in the following section).

\section{Identification of phenolics by LC-ESI-UHR-QqTOF-MS and HPLC}

The phenolic compounds of FPC, BPC, IDF-BPC and SDF-BPC extracts were identified and analysed using LC-ESI-UHR-QqTOFMS following the methodology of Monforte et al. ${ }^{40}$ Identification of main phenolic compounds was based on a comparison of the retention time and UV-visible and mass spectra with those obtained from the standard solutions, when available. The other peaks were tentatively identified comparing the information with available data reported in the literature. ${ }^{41,42}$ The elemental composition for these compounds was confirmed according to accurate mass $(5 \mathrm{mDa})$ and isotope rate calculations designated mSigma (<20) (Bruker Daltonics). ${ }^{40}$

The chromatographic analysis of FPC, BPC, IDF-BPC and SDFBPC extracts was performed following the methodology described by Oliveira et al. ${ }^{43}$ The main phenolic compounds identified (3-hydroxytyrosol, protocatechuic acid, tyrosol, vanillin, caffeic acid, $p$-coumaric acid and luteolin) were quantified by HPLC using external calibration curves constructed based on their maximum UV signal. The results were expressed as milligrams per $100 \mathrm{~g}$ DW. Hydroxytyrosol glucoside and tyrosol glucoside were respectively expressed as hydroxytyrosol and tyrosol equivalents in milligrams per $100 \mathrm{~g}$ DW.

\section{Antioxidant activity evaluation}

The FPC, BPC, IDF-BPC and SDF-BPC extracts were used to evaluate the AOX of OP powders according to the methods of $\mathrm{DPPH}^{\circ}{ }^{44}$ $\mathrm{ABTS}^{+45}$ and $\mathrm{ORAC}^{46}$ using a microplate reader (Fluostar, Optima; BMG Labtech, Ortenberg, Germany). The radical stock solutions were freshly prepared. All analyses were performed in triplicate and expressed in $\mu \mathrm{mol} \mathrm{L}{ }^{-1}$ Trolox-equivalents (TE) per gram DW.

\section{Screening of antimicrobial activity}

Bacterial species and test solutions

Bacillus cereus, methicillin-sensitive Staphylococcus aureus (MSSA), Salmonella enteritidis and Escherichia coli were obtained from American Type Culture Collection (ATCC 2599, ATCC 25923, ATCC 13076 and ATCC 25922, respectively). Yersinia enterocolitica was obtained from the National Collection of Type Cultures (NCTC 10406) and Listeria monocytogenes (13562) was kindly provided by Universidade Católica's Culture Collection. Inocula were grown overnight in MHB (Biokar Diagnostics, Beauvais, France) at $37{ }^{\circ} \mathrm{C}$. OP powders were suspended in MHB and sterilized by filtration through a $0.22 \mu \mathrm{m}$ filter (Millipore, Billerica, USA).

\section{Growth inhibition curves}

OP powder solutions between 1 and $3 \%(\mathrm{w} / \mathrm{v})$ were prepared and inoculated at $1 \%(\mathrm{v} / \mathrm{v})$ using an overnight inoculum of $10^{8} \mathrm{CFU} \mathrm{mL}{ }^{-1}$. Optical density (OD) at $660 \mathrm{~nm}$ was assessed for a $24 \mathrm{~h}$ period at $37{ }^{\circ} \mathrm{C}(1 \mathrm{~h}$ intervals) using a microplate reader, with the increase in OD being considered as a consequence of bacterial growth. A positive control (MHB inoculated without powder) and negative control (medium only) were used. ${ }^{44}$ Each condition was assayed in duplicate.

An inhibition percentage was calculated using the following formula:

$$
\text { Inhibition }(\%)=\frac{O D_{\text {control bacteria }}-O D_{\text {bacteria }}}{O D_{\text {control bacteria }}} \times 100
$$

where $\mathrm{OD}_{\text {control bacteria }}$ and $\mathrm{OD}_{\text {bacteria }}$ represent the $\mathrm{OD}$ (at $650 \mathrm{~nm}$ ) after $24 \mathrm{~h}$ of incubation of the control bacteria without OP powder and in the presence of the OP powder, respectively. ${ }^{47}$

\section{Minimum inhibitory and bactericidal concentrations}

Based on the results of the growth inhibition curves, the minimum inhibitory concentration (MIC) determination was performed only for the OP powders and microorganisms with relevant results. Test solutions ranging from 20 to $40 \mathrm{mg} \mathrm{mL}^{-1}$ were tested. MIC was determined based on the guidelines standard M07-A9. The minimum bactericidal concentration $(\mathrm{MBC})$ was determined as 
the lowest concentration tested that prevented bacterial growth. ${ }^{48}$ It was determined by inoculation of $20 \mu \mathrm{L}$ aliquots of negative wells (absence of turbidity in MIC determination) on plate count agar (PCA, Biokar Diagnostics, Beauvais, France), using the plate count technique. All assays were performed in quadruplicate.

\section{Functional properties}

The powder solubility in water was determined according to Cano-Chauca et al. ${ }^{49}$ The water-holding capacity (WHC) and oilholding capacity $(\mathrm{OHC})$ were determined by centrifugation. ${ }^{50}$ The $\mathrm{OHC}$ was determined under the same conditions as WHC using sunflower oil ( $0.92 \mathrm{~g} \mathrm{~mL}^{-1}$ density) and was expressed as grams of oil retained per gram of sample.

\section{Toxicity}

Cytotoxicity

Caucasian colon carcinoma (Caco-2; 8601020 European Collection of Authenticated Cell Cultures) cells were grown in Dulbecco's modified Eagle's medium (Lonza, Basel, Switzerland) supplemented with $10 \%(\mathrm{v} / \mathrm{v})$ heat-inactivated foetal bovine serum (Biowest, France), 1\% (v/v) Pen-Strep (Lonza, Basel, Switzerland) and 1\% (v/v) non-essential amino acids 100x (Lonza, Basel, Switzerland). All cells were incubated at $37^{\circ} \mathrm{C}$ in a humidified atmosphere with $5 \% \mathrm{CO}_{2}$. To evaluate the impact of OP powders upon Caco-2 viability, a 2,3-bis(2-methoxy-4-nitro-5-sulfophenyl)-2H-tetrazolium5-caboxanilide (XTT) assay was used. ${ }^{51}$ The cells were exposed to test solutions at concentrations of 20, 10, 5, 2.5 and $1.25 \mathrm{mg} \mathrm{mL}^{-1}$. LOPP was freshly prepared, while POPP was previously leached overnight in culture medium. All solutions were sterilized through filtering with a $0.22 \mu \mathrm{m}$ filter. Plain culture medium was used as a negative control. All assays were performed in quintuplicate.

\section{Mutagenicity}

The mutagenic effect was assessed using the Ames test with Salmonella typhimurium strain (TA98) according to Maron and Ames. ${ }^{52}$ The OP powders were tested at different concentrations (15-1000 $\mu \mathrm{g}$ of sample per plate). Positive control (quercetin at $20 \mu \mathrm{g}$ per plate) and solvent control ( $0.05 \mathrm{~mL}$ of DMSO per plate) were carried out. For a powder to be considered positive, it had to produce at least a twofold increase in the mean revertant colonies per plate over the mean revertant colonies per plate of the positive control. Three plates per two separate experiments were assayed for each concentration tested and for positive and negative controls.

\section{Statistical analysis}

Data obtained for all parameters were analysed using a Student $t$ test and two-way analysis of variance (ANOVA). Tukey's post hoc test was applied for comparison of means; differences were considered significant at $P<0.05$. The Shapiro-Wilk test was used to evaluate the normality of data distribution. R software (https:// www.r-project.org/) was used to carry out the statistical analysis.

\section{RESULTS AND DISCUSSION}

\section{Chemical and structural characterization of OP powders}

The physicochemical composition of each OP powder, as presented in Table 1, demonstrates that, overall, higher ash, soluble sugar and organic acid contents were present in LOPP, while POPP exhibited a higher crude protein and fat contents. Similar results were reported regarding OP liquid and pulp fraction. ${ }^{28}$ In agreement with their ash content, OP powders also have significantly different amounts of minerals. Potassium was the predominant mineral in both OP powders, as observed before in olive mill by-products. ${ }^{23}$ The amount of potassium was notably higher in LOPP $\left(54.31 \mathrm{~g} \mathrm{~kg}^{-1} \mathrm{DW}\right)$ in comparison to POPP $\left(17.56 \mathrm{~g} \mathrm{~kg}^{-1}\right.$ DW), probably due to the water solubility of the minerals. The high amount of potassium, low sodium content and a mixture of other minerals (phosphorus, magnesium and calcium) of LOPP could be explored by the food industry, not only in the mineral fortification of foods (potentially as a taste agent/replacer of sodium chloride) but also to add potential health benefits. For instance, a higher consumption of potassium is associated with the prevention of cardiovascular disease and the maintenance of normal blood pressure. ${ }^{35,54}$ On the other hand, the mixture of other minerals could be an asset to mask the bitter taste of potassium, allowing LOPP to be used as a taste agent.

LOPP also exhibited a higher amount of soluble sugars and organic acids than POPP. The HPLC analysis of soluble sugars and organic acids allowed the identification of mannitol and formic acid as the most representative sugar and organic acid, respectively (Table 1). The quantification of soluble sugars in OPderived ingredients was also achieved in previous work. ${ }^{26}$ PérezJiménez et al. ${ }^{26}$ obtained powder with a similar amount of fructose and a smaller amount of glucose or mannitol compared to LOPP, but POPP exhibited a smaller amount of all the soluble sugars quantified. These differences arose mainly due to the liquid-solid fractionation process to obtain LOPP and POPP from OP. The high mannitol content of LOPP $\left(141.11 \pm 12.45 \mathrm{~g} \mathrm{~kg}^{-1}\right.$ DW) could be an asset to its application as a food ingredient. Mannitol has been reported as an antioxidant compound, as well as a food preservative (it increases food shelf life by reducing sugar crystallization) and also as being a non-metabolizable sweetener (since its uptake is independent of insulin). ${ }^{54}$

Organic acids have been scarcely studied in OP-derived ingredients. However, the organic acid composition of LOPP supports its applicability as a food preservative and as a taste agent. Formic acid, which was the main organic acid found in LOPP (10.27 \pm 0 . $\left.72 \mathrm{~g} \mathrm{~kg}^{-1} \mathrm{DW}\right)$, is known for its antimicrobial action. ${ }^{55}$ Lactic and acetic acids, detected in smaller amounts (2.62-4.15 $\left.\mathrm{g} \mathrm{kg}^{-1} \mathrm{DW}\right)$, are also commonly used as antimicrobial agents, but could also be applied as flavour enhancers, as reported before in fish sauce. $^{56}$

The relatively high crude protein $\left(118.24 \pm 1.24 \mathrm{~g} \mathrm{~kg}^{-1} \mathrm{DW}\right)$ and fat $\left(119.54 \pm 6.99 \mathrm{~g} \mathrm{~kg}^{-1} \mathrm{DW}\right)$ contents of POPP are an indicator that this powder may be a rich source of amino acids and fatty acids. Similar protein content ${ }^{28}$ and fat content ${ }^{57}$ were reported in the literature regarding OP-derived powders. OP has not been considered a reputable source of protein (less than $8 \% \mathrm{DW}){ }^{58}$ However, the dry fractionation approach applied to obtain POPP had a small concentrating effect ${ }^{59}$ in line with the results of Ying et $a l^{28}$ On the other hand, the OP powder developed by Crizel et al. ${ }^{57}$ without fractionation of OP (drying at $55^{\circ} \mathrm{C}$ and discarding particles greater than $125 \mathrm{~mm}$ ) in comparison to POPP presented only half of the protein of POPP, but similar fat content.

The quantitative composition of total amino acids and fatty acids was achieved (Table 1). Regarding the amino acid profile and the amino acid pool, POPP maintained the values reported to OP. ${ }^{4,58}$ Amino acids Glu $\left(21.63 \pm 2.58 \mathrm{~g} \mathrm{~kg}^{-1} \mathrm{DW}\right)$ and Asp $\left(22.11 \pm 2.32 \mathrm{~g} \mathrm{~kg}^{-1} \mathrm{DW}\right)$ showed the highest values. These amino acids are sour stimuli and cause umami taste as the sodium salt, ${ }^{35}$ which could be an asset for POPP application in meat products, for example. Concerning fatty acids, POPP exhibited a higher 


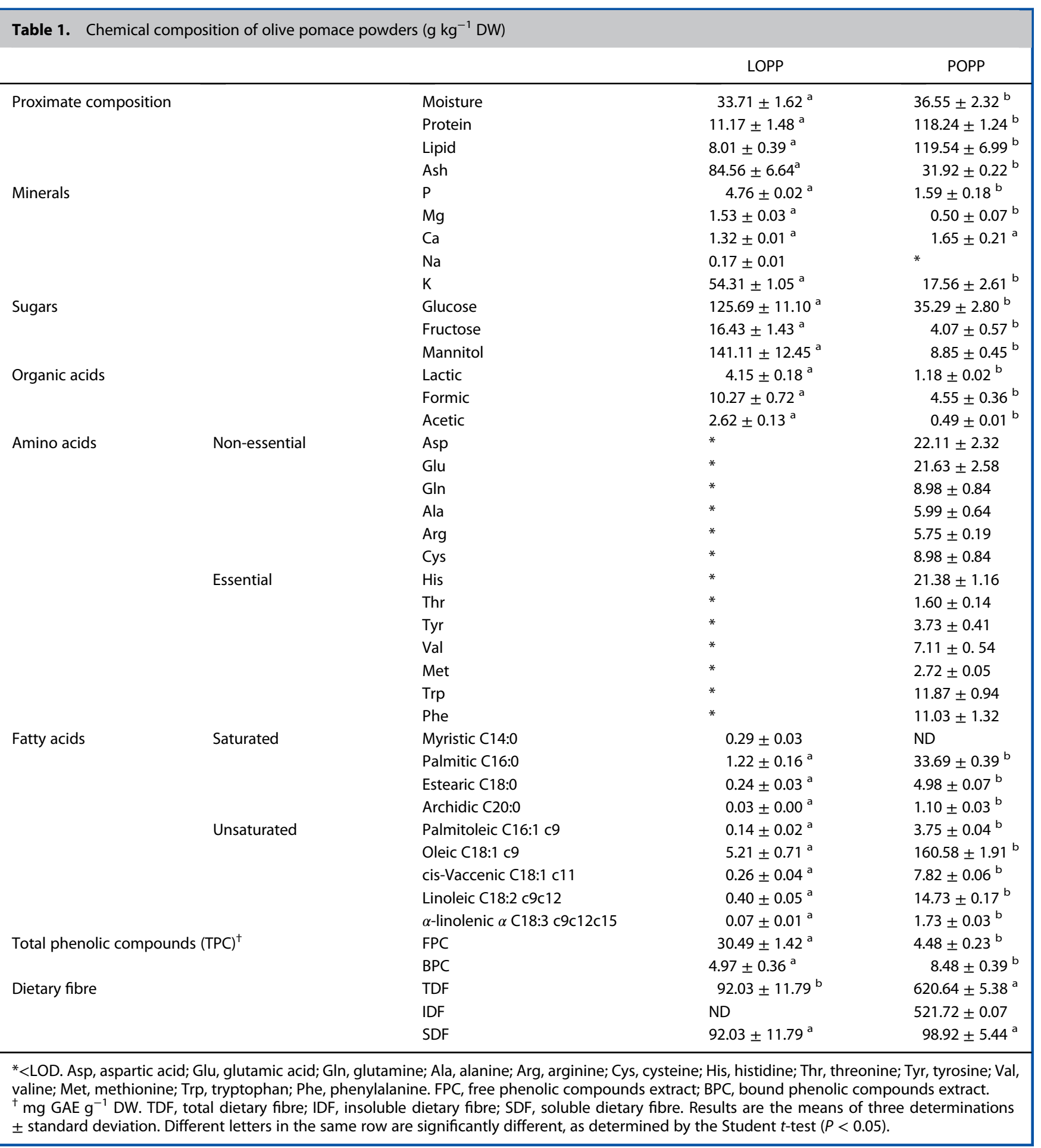

level of oleic acid (corresponding to $70 \%$ of total fatty acids) followed by linoleic acid (corresponding to 6\%). A similar relative percentage of these UFAs were reported for olive oil and an OPderived powder. ${ }^{26}$ The UFA composition of POPP is similar to that of commercial olive oil. Thus, there are expected to be health benefits like reduction of cholesterol/triglycerides or even obesity prevention (by restoring the gut bacteria composition) from POPP application. $^{60,61}$

\section{Bioactive phytochemical composition of OP powders}

A complete characterization of the OP powder phenolic content (TPC) was performed (Table 1), including the usually determined FPC fraction, as well as the BPC fraction which is commonly ignored. ${ }^{16}$ LOPP exhibited a significantly higher TPC for FPC $\left(30.49 \pm 1.42 \mathrm{mg} \mathrm{GAE} \mathrm{g}^{-1} \mathrm{DW}\right)$ than POPP $(4.48 \pm 0.23 \mathrm{mg}$ GAE $\left.\mathrm{g}^{-1} \mathrm{DW}\right)(P>0.05)$. Regarding BPC, POPP showed the highest TPC value $(P>0.05)$. The TPC value of FPC in LOPP was very similar 


\begin{tabular}{|c|c|c|c|c|c|c|c|c|}
\hline & \multicolumn{6}{|c|}{ Monosaccharide composition } & \multirow[b]{2}{*}{$\mathrm{RP}$} & \multirow[b]{2}{*}{$\mathrm{BPC}^{\ddagger}$} \\
\hline & Glucose & Xylose & Galactose & Arabinose & Mannose & NS & & \\
\hline LOPP SDF & $=28.46 \pm 3.60^{a}$ & * & $62.54 \pm 10.08^{a}$ & $48.14 \pm 5.60^{a}$ & $8.07 \pm 1.37$ & 147.21 & $16.47 \pm 2.46^{a}$ & $14.56 \pm 1.74^{a}$ \\
\hline POPP IDF & $167.91 \pm 12.56^{b}$ & $95.06 \pm 7.49$ & $8.55 \pm 1.02^{c}$ & $33.54 \pm 2.17^{b}$ & * & 305.06 & $49.52 \pm 2.87^{b} 7.46 \pm 0.03281 .64 \pm 9.35$ & $7.41 \pm 0.62^{b}$ \\
\hline SDF & $=14.18 \pm 1.90^{c}$ & & $\begin{array}{l}25.88 \pm \\
0.53^{c}\end{array}$ & $39.07 \pm 1.86^{c}$ & * & 79.13 & $81.25 \pm 4.61^{c}$ & $7.63 \pm 0.30^{b}$ \\
\hline \multicolumn{9}{|c|}{$\begin{array}{l}\text { * }<\text { LOD. NS, neutral sugars; UA, uronic acids; RP, resistant protein; KL, Klason lignin; BPC, bound phenolic compounds; TDF, total dietary fibre; IDF, insol- } \\
\text { uble dietary fibre; SDF, soluble dietary fibre. } \\
+ \text { mg GUAE }{ }^{-1} \text { fibre DW. } \\
{ }^{\dagger} \text { mg GAE }{ }^{-1} \text { fibre DW. Results are the means of three determinations } \pm \text { standard deviation. Different letters in the same column are significantly } \\
\text { different, as determined by ANOVA }(P<0.05) \text {. }\end{array}$} \\
\hline
\end{tabular}

to the value obtained before for freeze-dried liquid fraction powder obtained by Ying et $a l .{ }^{28}$ In the same study, a freeze-dried pulp fraction was also obtained, which exhibited a higher TPC value for FPC (ca $20 \mathrm{mg} \mathrm{GAE} \mathrm{g}^{-1}$ DW) than POPP. These differences most likely arise from the different drying process employed by Ying et $a .^{28}$ (freeze drying) and in this study (oven drying). The use of temperature to obtain POPP is probably the main reason for its lower TPC value. ${ }^{22,23}$ Other OP-derived powder reported in the literature prepared using temperature $\left(55^{\circ} \mathrm{C}\right)$ exhibited a lower TPC (ca $10 \mathrm{mg} \mathrm{GAE} \mathrm{g}^{-1} \mathrm{DW}$ ) in comparison with the one obtained in our study that used a drying temperature of $90{ }^{\circ} \mathrm{C}^{57}$ The bound phenolic content was not estimated in either study. Only PérezJiménez et al. $^{26}$ evaluated BPC of their OP-derived powder obtained without separation of the liquid and solid fraction of $\mathrm{OP}$ and using vacuum drying. The BPC value obtained in the study mentioned above (ca $16 \mathrm{mg} \mathrm{GAE} \mathrm{g}^{-1} \mathrm{DW}$ ) is analogous with the sum of BPC of LOPP $\left(4.97 \pm 0.36 \mathrm{mg} \mathrm{GAE} \mathrm{g}^{-1} \mathrm{DW}\right)$ and POPP $\left(8.48 \pm 0.39 \mathrm{mg} \mathrm{GAE} \mathrm{g}^{-1} \mathrm{DW}\right)$. The higher BPC value of POPP was possibly related to its superior IDF content. ${ }^{62}$ Other studies with vegetables and fruits reported that BPC was mainly associated with IDF. ${ }^{62,63}$

POPP showed a substantially higher amount of TDF (620.64 $\left.\pm 5.38 \mathrm{~g} \mathrm{~kg}^{-1} \mathrm{DW}\right)$, where IDF $\left(521.72 \pm 0.07 \mathrm{~g} \mathrm{~kg}^{-1} \mathrm{DW}\right)$ was the main component (Table 1). The amount of SDF of both OP powders was similar (9-10\% DW). POPP exhibited a higher TDF, IDF and SDF content than the values recorded for other OPderived powders. ${ }^{26,28,57}$ The process used by Ying et al. ${ }^{28}$ to remove stones and the longer time of drying ( $24 \mathrm{~h})$ at lower temperatures $\left(55^{\circ} \mathrm{C}\right)$ of Crizel et al..$^{57}$ seem to affect TDF content negatively. On the other hand, the defatting process applied to OP by Pérez-Jiménez et al. ${ }^{26}$ only lowered IDF and TDF content. In brief, POPP could be considered an excellent source of DF and might be applied as a fibre fortifier. Indeed, POPP exhibited higher TDF content $\left(62.06 \pm 0.54 \mathrm{~g}(100 \mathrm{~g})^{-1} \mathrm{DW}\right)$ than wheat bran (44\%) and oat bran (23.8\%) generally applied in fibre fortification of foods. ${ }^{57}$

The determination of chemical structure (i.e. monosaccharides, lignin, uronic acids, phenolics) is fundamental for understanding the several health benefits of fibre. Despite the OP fibre richness, until now the fibre profile of the OP-derived powders has been neglected. The results of monosaccharide, lignin and uronic acid composition of IDF and SDF among OP powders are presented in Table 2. The monosaccharide composition of the SDF fraction of OP powders was very distinct. POPP revealed the highest content of uronic acids, which could be explained by the higher concentration of pectins reported in our previous work for OP solid fraction (data not shown). Pectins have essential roles in the regulation and protection of the gastrointestinal tract due to their potential prebiotic effect. ${ }^{64}$ The SDF monosaccharide profile revealed a higher soluble hemicellulose-rich character for LOPP than POPP. The main component of LOPP was galactose (ca $43 \%$ ), followed by arabinose (ca 33\%) and glucose (ca 19\%).

The IDF profile of POPP revealed a higher content of glucose ( $c a$ $55 \%$ of total neutral sugars) followed by xylose (ca $31 \%$ of total neutral sugars). Hemicellulose (as the sum of xylose, galactose and arabinose) was less abundant in the IDF from POPP than cellulose (glucose monomers). Based on the monosaccharide composition results, the IDF fraction of POPP was mostly a source of insoluble arabinoxylans and cellulose. However, the main component of IDF of POPP was Klason lignin (ca $43 \%$ of total IDF composition), in line with previous studies of OP fibre composition. ${ }^{4}$ Arabinoxylans are essential functional ingredients in baked products and have been associated with various biological functions, including positive effects on gut microbiota. ${ }^{65}$ On the other hand, the lignin as a complex macromolecule with linked phenolic compounds (BPC) protects these compounds through the gastrointestinal tract until the colon, where they play a beneficial role in gut health. ${ }^{66}$

In the past, DF and phenolics were assessed separately as nonrelated compounds. However, phenolics are a constituent of DF with a significant role in its properties. ${ }^{62}$ To the best of our knowledge, the role of phenolics in DF has never been investigated in OP-derived ingredients. According to the TPC results, the OP powder fibre fractions showed different amounts of phenolics (Table 2). Comparing the BPC extracts of LOPP, SDF-BPC extract displayed three times greater levels of TPC than BPC extract, which allowed the conclusion to be drawn that BPC of LOPP was mainly linked to fibre. The IDF-BPC and SDF-BPC extracts of POPP exhibited similar TPC contents. Comparing the TPC of BPC extracts from POPP and their fibre fractions, it is evident that DF plays a crucial role as a carrier of more than half of total BPC ( $c a$ $54 \%)$. As expected, the IDF fraction presented the highest amount of BPC (ca 45\%), but SDF also presents some phenolics linked to them. Therefore, in POPP, it is possible to hypothesize the existence of phenolics linked to other macromolecules besides DF, namely protein and lipids.

In previous studies, the occurrence of interactions between lipids/proteins and phenolics and consequent protection of phenolics through the gastrointestinal tract has been described. ${ }^{67}$ In protein-phenolic association, the core interactions are noncovalent hydrophobic stabilized by hydrogen bonds, mainly with 


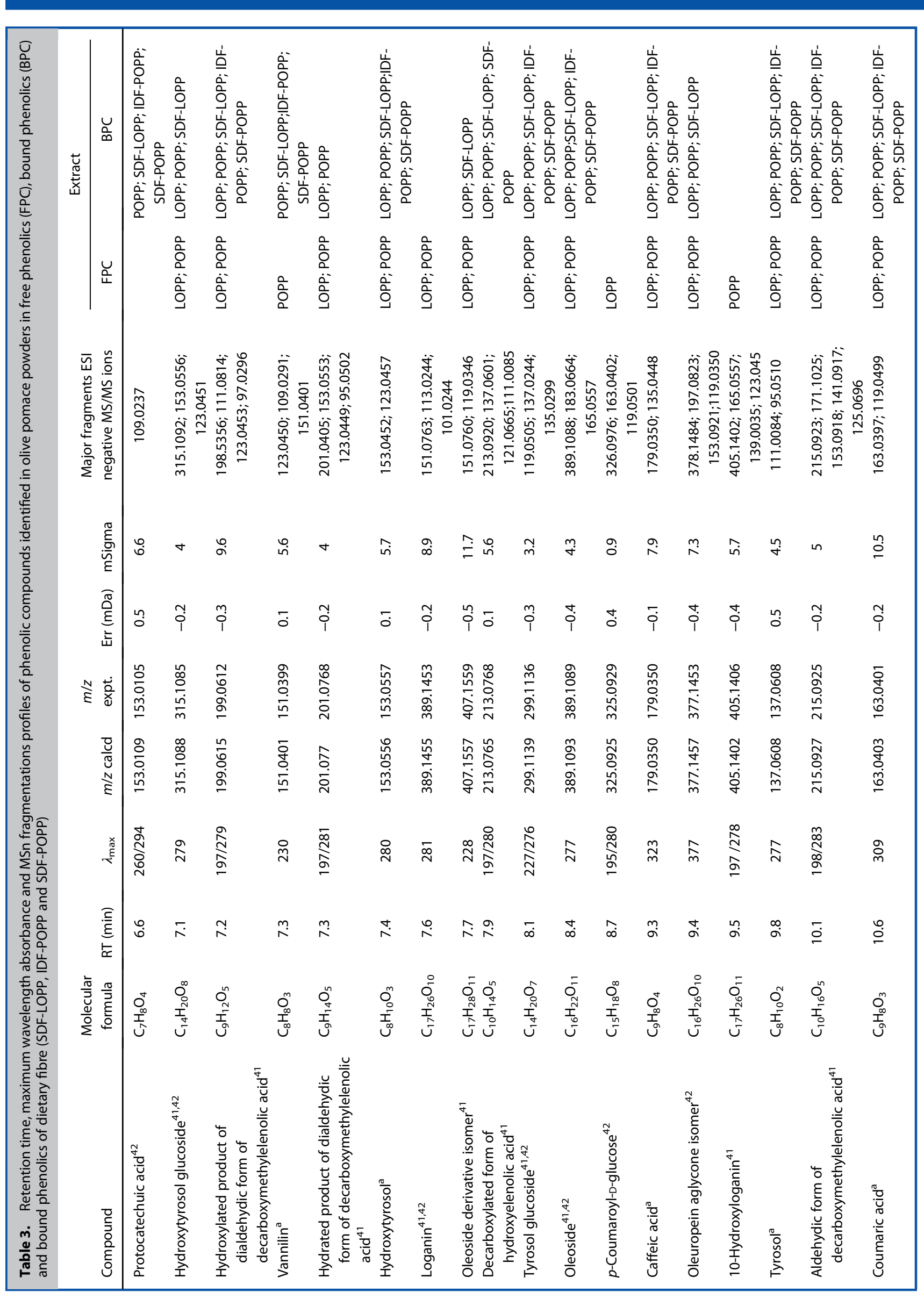




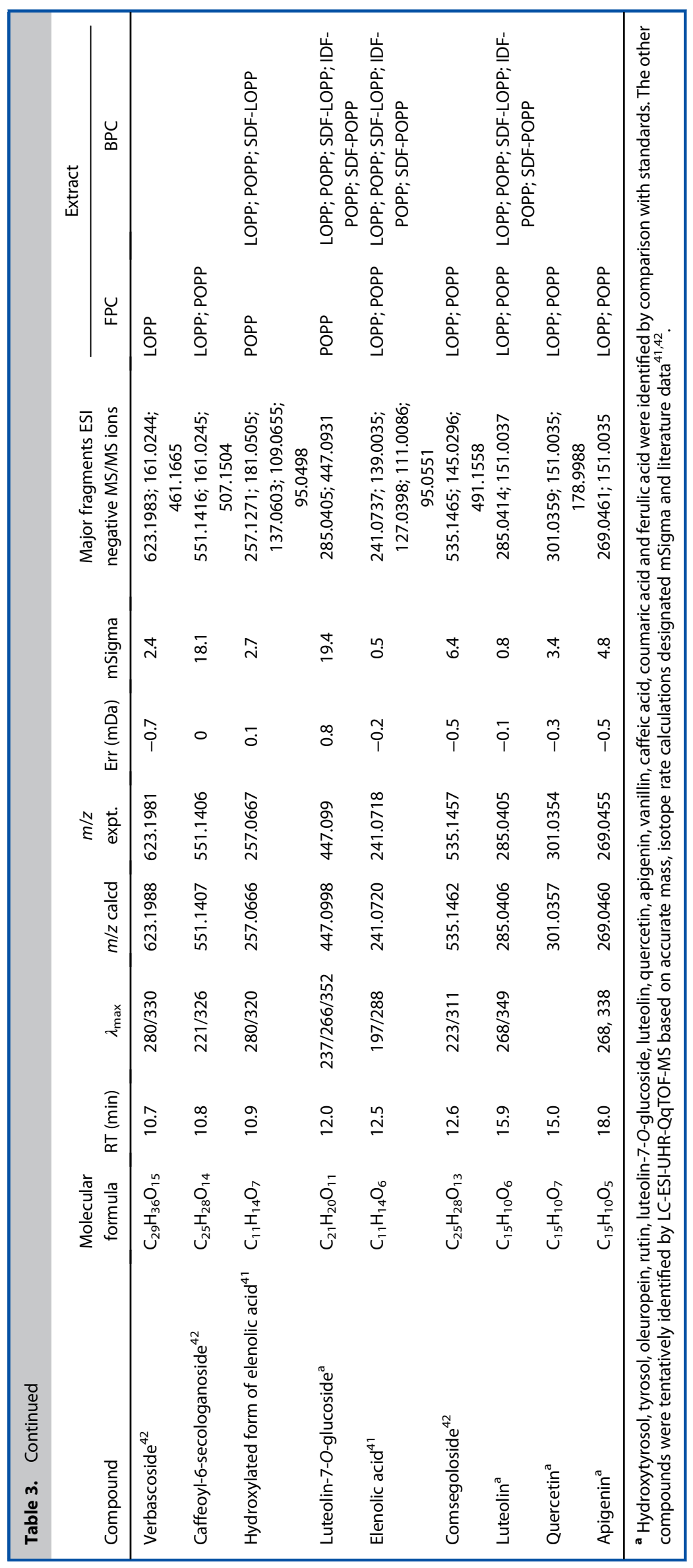



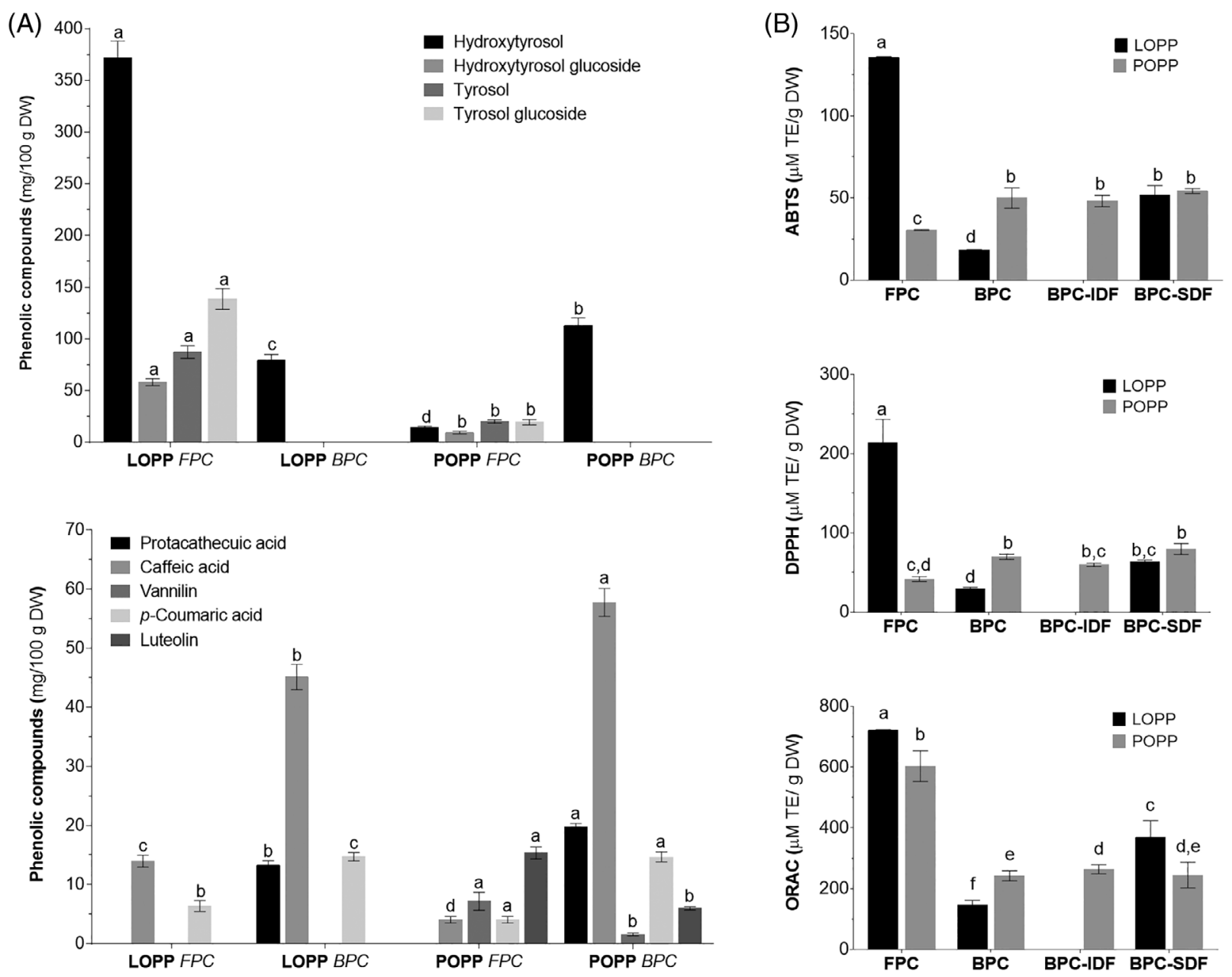

Figure 1. (A) Phenolic profile of OP powders and (B) antioxidant activity using ABTS, DPPH and ORAC methods of free and bound phenolic compounds of OP powders and fibre fractions. FPC, free phenolic compounds extract; BPC, bound phenolic compounds extract; IDF, insoluble dietary fibre; SDF, soluble dietary fibre. Results are the means of three determinations \pm standard deviation. Different letters in the same column are significantly different, as determined by ANOVA $(P<0.05)$.

polar amino acids (e.g. aspartic acid, glutamic acid, cysteine). ${ }^{69}$ POPP, as highlighted above, exhibited a high content in polar amino acids, which could establish hydrogen bonds with phenolics. Nevertheless, in the case of lipids, not only could lipids protect phenolics, but phenolics could also protect lipids from peroxidation. ${ }^{69}$ The lipid-phenolic interaction could be an asset to POPP lipids stability.

Other compounds that remain associated with IDF are proteins. ${ }^{63}$ The amount of resistant protein of the IDF fraction of POPP was measured (Table 2). The resistant protein content obtained was small (1\%) when compared to other plant foods. ${ }^{63}$

Regarding the identification and quantification of phenolic compounds of OP powders and fibre fractions, the LC-ESI-UHRQqTOF-MS and HPLC results are reported in Table 3 and Fig. 1, respectively. The analysis allowed identification and quantification of the phenolic classes present in the OP powders. Regarding specific phenolic classes, mainly simple or dihydroxy phenolics were identified in FPC and BPC fractions of OP powders, more specifically hydroxytyrosol and tyrosol.

Hydroxytyrosol stands out as an abundant phenolic in olive byproducts with higher added value., ${ }^{3,5}$ Additionally, one derivative of hydroxytyrosol was also identified, namely hydroxytyrosol glucoside. This phenolic was identified in all extracts, except for extracts from POPP fibre. Hydroxytyrosol glucoside is a polar compound with a considerable size and some degree of glycosylation. $^{70}$ Therefore, it is reasonable that it could only be linked to the protein of POPP due to its high molecular weight. ${ }^{68}$ Another monoglycoside identified in a substantial amount in FPC and BPC extracts was tyrosol glucoside. Other compounds like loganin, verbascoside, caffeoyl-6-secologanoside, quercetin and apigenin were only identified in FPC extract of both OP powders and $p$-coumaroyl-D-glucose and comsegoloside were just detected in FPC extract of LOPP. On the other hand, protocatechuic acid and an elenolic acid derivative (decarboxylated form of hydroxyelenolic acid) ${ }^{41}$ were exclusively found in BPC extracts. Hydroxybenzoic acids such as protocatechuic acid are typically found linked to structural components like cellulose and lignin, which are the main components of the abundant IDF fraction of POPP. ${ }^{71}$ All the compounds reported have been identified before in olive oil and olive by-products. ${ }^{41,42}$

The HPLC quantification of the principal components of FPC and BPC extracts from OP powders was assessed (Fig. 1). Concerning the content of hydroxytyrosol, tyrosol and derivatives (FPC: $655.96 \mathrm{mg}(100 \mathrm{~g})^{-1}$ DW; BPC: $\left.79.00 \mathrm{mg}(100 \mathrm{~g})^{-1} \mathrm{DW}\right)$ in LOPP, 

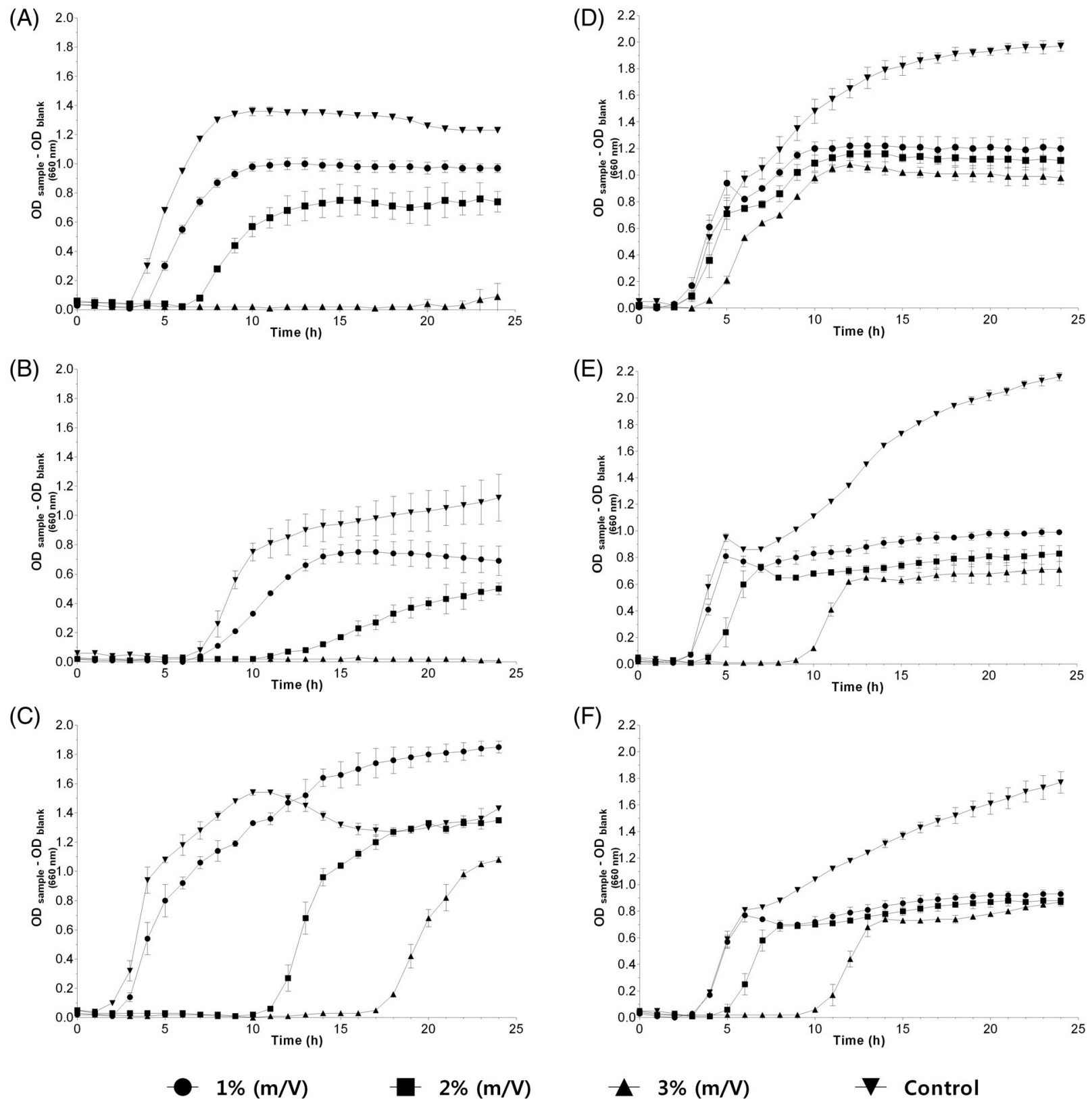

Figure 2. Time inhibition curves drawn at different LOPP concentrations (1, 2 and 3\%). (A) MSSA; (B) Listeria monocytogenes; (C) Bacillus cereus; (D) Escherichia coli; (E) Yersinia enterocolitica; (F) Salmonella enteritidis. Results are the means of three determinations \pm standard deviation.

it was substantial, and thus could potentially allow obtaining the benefits of the health claim 'protection of LDL particles from oxidative damage' with daily consumption of less than $1 \mathrm{~g}$.

As expected, the content of hydroxytyrosol glucoside and hydroxycinnamic acids (caffeic and $p$-coumaric acids) was higher in BPC than in FPC of POPP due to their linkage to cellulose, lignin and protein through ester linkages. ${ }^{71}$ This considerable amount of BPC phenolics linked to fibre cannot be absorbed in the small intestine but could be released and metabolized by bacterial enzymes of the gut flora to generate protective health effects, including prebiotic effects, antimicrobial action against pathogens and antioxidant activity from phenolic metabolites. ${ }^{29}$ Therefore, the potential gut health benefits of POPP as source of ADF needs to be assessed with further detail in future studies.

\section{Bioactivity of OP powders}

Regarding the AOX, LOPP showed the highest AOX value by ABTS, DPPH and ORAC (Fig. 1), in accord with its higher TPC. In LOPP, the higher TPC of FPC extracts than BPC extracts could explain the differences in the AOX of FPC and BPC extracts. LOPP exhibited a DPPH value lower than that reported in the literature for fresh OP (ca $100 \mu \mathrm{mol} \mathrm{TE} \mathrm{g}^{-1} \mathrm{DW}$ ), but the ORAC value obtained was very similar (ca $\left.950 \mu \mathrm{mol} \mathrm{TE} \mathrm{g}^{-1} \mathrm{DW}\right) .^{72}$ The lower DPPH value could be linked to the lower lipophilic nature of antioxidants present in LOPP, which are retained in POPP. DPPH and ABTS assays are examples of electron transfer methods, while ORAC is a hydrogen atom transfer method. However, DPPH is more efficient for measuring AOX of less polar compounds than ABTS and ORAC, due to its solubilization only in organic media. ${ }^{73}$ 

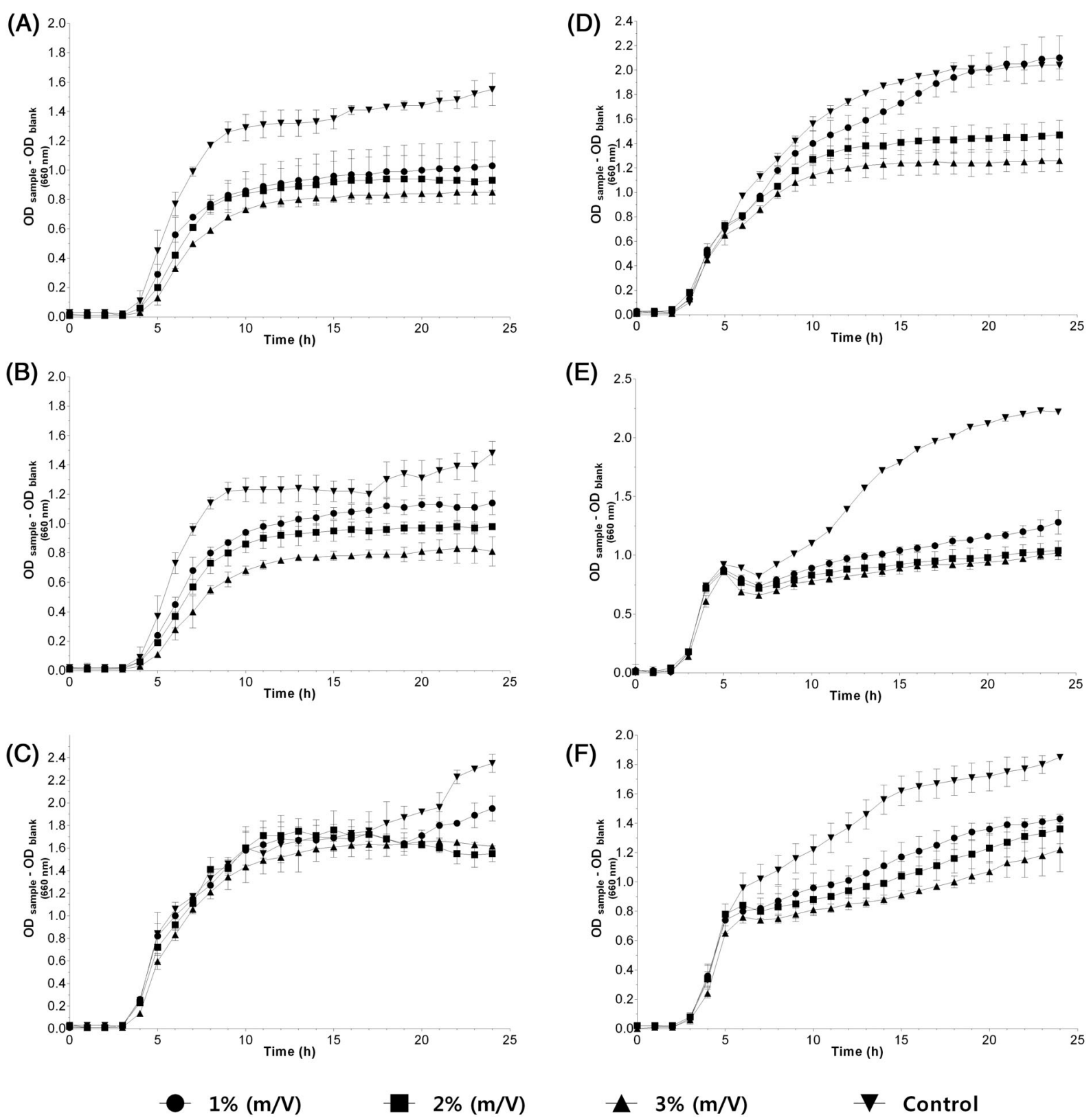

Figure 3. Time inhibition curves drawn at different POPP concentrations (1, 2 and 3\%). (A) MSSA; (B) Listeria monocytogenes; (C) Bacillus cereus; (D) Escherichia coli; (E) Yersinia enterocolitica; (F) Salmonella enteritidis. Results are the means of three determinations \pm standard deviation.

Concerning ABTS, in the literature, an OP-derived powder used to fortify cereal foods reported a lower ABTS value (ca $79 \mu \mathrm{mol}$ TE $\mathrm{g}^{-1} \mathrm{DW}$ ) than LOPP but higher than POPP. The higher ABTS value of LOPP arises probably from the lower drying temperature $\left(35^{\circ}\right.$
C) used, but the no application of OP fractionation explains the lower ABTS value of POPP. ${ }^{74}$ Once again, to the best of our knowledge, BPC fractions of OP food ingredients were neglected in most studies published regarding this topic.

Table 4. Functional properties of olive pomace powders (LOPP and POPP)

\begin{tabular}{llrl} 
& \multicolumn{1}{c}{ LOPP } & POPP & Standard \\
\hline Solubility (\%) & $93.22 \pm 1.01^{\mathrm{a}}$ & $18.62 \pm 0.09^{\mathrm{b}}$ & - \\
WHC (g water g & $1.86 \pm 0.05^{\mathrm{a}}$ & $1.23 \pm 0.01^{\mathrm{b}}$ \\
OHC (g oil g $\left.{ }^{-1} \mathrm{DW}\right)$ & - & $2.67 \pm 0.23^{\mathrm{a}}$ & $2.41 \pm 0.19^{\mathrm{b}}$ \\
\hline
\end{tabular}

Standard: cellulose; WHC, water holding capacity; $\mathrm{OHC}$, oil holding capacity. Results are the means of three determinations \pm standard deviation. Different letters in the same column are significantly different, as determined by the Student $t$-test $(P<0.05)$. 


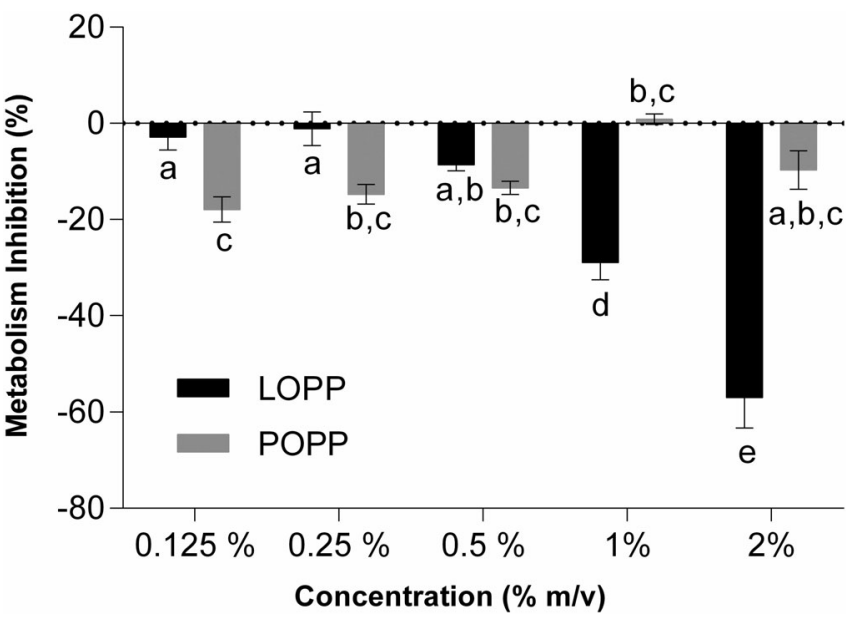

Figure 4. Metabolism of Caco-2 intestinal cells in the presence of OP powder at concentrations of $2,1,0.5,0.25$ and $0.125 \%(\mathrm{w} / \mathrm{v})$. Results are the means of three determinations \pm standard deviation. Different letters in the same column are significantly different, as determined by ANOVA $(P<0.05)$.

POPP exhibited a higher AOX according to ABTS, DPPH and ORAC results to BPC extract, due to its higher TPC. Similar results were observed for rice bran and other insoluble-rich food sources. ${ }^{75}$ Additionally, the AOX of the FPC fraction of POPP by ORAC and DPPH was higher than results reported for other vegetable by-product powders, namely fruit (passion fruit, pineapple and guava) and vegetable (asparagus). ${ }^{32}$

In our study, the AOX of BPC extracts from IDF and SDF fractions was also evaluated. Consistent with TPC results, regarding the BPC extracts, the fibre fraction extract from LOPP exhibited a higher AOX. This higher value validates the importance of fibre as a carrier of antioxidant compounds in LOPP. In POPP, the AOX values obtained together with higher fibre content allowed one to claim its character as an ADF source, since the AOX of POPP fibre fractions corresponded to more than half $(50-60 \%)$ of the total $A O X$ of BPC.

Concerning antimicrobial activity, growth inhibition curves were constructed for selected microorganisms, in the presence of OP powders at a concentration of 1,2 and $3 \%(w / v)$, as measured by turbidity at $660 \mathrm{~nm}$. LOPP (Fig. 2) and POPP (Fig. 3) were capable of inhibiting, at some level, all microorganisms tested. Only the growth of Gram-positive MSSA and L. monocytogenes was entirely inhibited by $3 \%$ LOPP (MIC), while all other concentrations tested (i.e. sub-MIC concentrations) were capable of reducing microbial growth, while causing an increase of lag phase duration. In the case of $B$. cereus, the growth was completely inhibited by $16 \mathrm{~h}$. Gram-positive microorganisms were more susceptible to LOPP. The growths of Gram-negative microorganisms tested ( $E$. coli, S. enteritidis, $Y$. enterocolitica) were delayed to half at 2 and $3 \%$ of LOPP and also suffered a delay on the log phase. POPP ( 2 and $3 \%$ ) induced a reduction of the growth and a delay of the log phase of all the microorganisms tested, except for $B$. cereus.

To determine the MBC for LOPP concerning MSSA and L. monocytogenes, concentrations of 2.5, 3, 3.5 and $4 \%(\mathrm{w} / \mathrm{v})$ were plated. The 4 and 3\% LOPP concentrations killed 99\% of MSSA and L. monocytogenes, respectively, and thus LOPP had a bactericidal effect.

The higher antimicrobial activity of LOPP may be attributed to the presence of higher amounts of several components, namely minerals (e.g. potassium) and some organic acids such as formic, lactic and acetic acids, besides the higher concentration of phenolics like hydroxytyrosol and its derivatives with well-documented antimicrobial activity. ${ }^{76}$ These values for antimicrobial activity support the potential application of OP powders not only as functional ingredients but also as preservatives.

\section{Functional properties of OP powders}

To determine the OP powder functionality in a food matrix, it is essential to know the functional properties, i.e. solubility, WHC and OHC (Table 4). LOPP exhibited a solubility of $93.22 \%$, due to its rich content in soluble sugars, ash and SDF. Contrarily, POPP revealed a lower solubility (18.62\%), owing to its richness in IDF. The WHC and OHC of POPP were $1.86 \mathrm{~g}$ water $\mathrm{g}^{-1} \mathrm{DW}$ and 2.67 $\pm 0.23 \mathrm{~g} \mathrm{oil} \mathrm{g}^{-1}$, respectively. Crizel et al. ${ }^{57}$ reported higher WHC and similar $\mathrm{OHC}$ values for their OP powder. The higher WHC value can be attributed to the greater amount of IDF of POPP. ${ }^{57}$ Other co-products exhibited lower and similar values of WHC: passion fruit albedo by-product $\left(1.80 \mathrm{~g} \mathrm{~g}^{-1}\right)$ and date by-product paste $\left(1.33 \mathrm{~g} \mathrm{~g}^{-1}\right) .^{77}$

Table 5. Numbers of revertant colonies induced by olive pomace powders (LOPP and POPP) in Salmonella typhimurium TA98 strain with metabolic activation (S9 mix)

\begin{tabular}{|c|c|c|c|c|c|}
\hline \multirow[b]{2}{*}{ Dose ( $\mu$ g per plate) } & \multicolumn{3}{|c|}{ Revertant colonies per plate } & \multicolumn{2}{|c|}{ Mutagenicity index ${ }^{a}$} \\
\hline & & LOPP & POPP & LOPP & POPP \\
\hline 10 & & $20.3 \pm 8.6$ & $21.7 \pm 3.5$ & 0.12 & 0.13 \\
\hline 25 & & $18.0 \pm 2.7$ & $20.3 \pm 5.0$ & 0.11 & 0.12 \\
\hline 50 & & $20.3 \pm 2.5$ & $18.0 \pm 4.4$ & 0.12 & 0.11 \\
\hline 100 & & $18.3 \pm 6.4$ & $17.7 \pm 5.7$ & 0.11 & 0.11 \\
\hline 250 & & $15.3 \pm 5.5$ & $18.3 \pm 2.5$ & 0.09 & 0.11 \\
\hline 500 & & $14.5 \pm 2.1$ & $12.5 \pm 2.1$ & 0.09 & 0.07 \\
\hline 1000 & & $25.0 \pm 2.8$ & $27.5 \pm 9.1$ & 0.15 & 0.16 \\
\hline Blank control & $18.0 \pm 2.5$ & & & & \\
\hline Control (quercetin) $20 \mu \mathrm{g}$ per plate & $168.0 \pm 54.0$ & & & & \\
\hline
\end{tabular}


$\mathrm{OHC}$ is associated with the chemical and physical structures of polysaccharides. ${ }^{57}$ LOPP showed similar OHC to POPP since the content of SDF of both powders was similar. OHC values of OP powders were higher than those of other plant fibres: apple $\left(0.60-1.45 \mathrm{~g} \mathrm{~g}^{-1}\right)$ and grapefruit (1.20-1.52 $\left.\mathrm{g} \mathrm{g}^{-1}\right)$; as well as other by-products: mango $\left(1.60 \mathrm{~g} \mathrm{~g}^{-1}\right)$, passion fruit $\left(0.90 \mathrm{~g} \mathrm{~g}^{-1}\right)$ and guava $\left(0.70 \mathrm{~g} \mathrm{~g}^{-1}\right)$ co-products. ${ }^{32}$ The higher ratio of IDF of POPP explains the results obtained. The modification of POPP (grinding and chemical and enzymatic hydrolysis) could be interesting for enhancing its SDF content and, consequently, its functional properties and health properties. ${ }^{78}$

\section{Safety tests}

The cytotoxicity and mutagenicity of OP powders were studied for the first time, to the authors' knowledge. The cell viability was evaluated using the XTT cell proliferation assay with Caco-2 intestinal cells. In this assay, XTT is reduced by mitochondrial dehydrogenases in metabolically viable cells. XTT assay is widely utilized in cell proliferation as well as drug sensitivity tests. ${ }^{79}$ The OP powders presented no cytotoxicity at the assayed concentration range (Fig. 4). The Ames assay was used to evaluate the mutagenicity. The different concentrations of OP powders added to S. typhimurium culture did not influence cell viability (Table 5). None of the dilutions was mutagenic in strain TA98 under the conditions used in this assay, which indicates the absence of mutagens that cause frameshift mutations. The absence of cytotoxicity and mutagenicity for OP powders indicates that the present components did not induce cell and DNA damage, and for that reason, they can be considered safe at the concentrations tested.

\section{CONCLUSIONS}

OP powders demonstrated potential for use as multifunctional ingredients with application in food formulation. LOPP could be used simultaneously as a source of mannitol, potassium and hydroxytyrosol and POPP as a source of antioxidant dietary fibre and oleic/linoleic acid. The high antioxidant and antimicrobial activities exhibited by LOPP could be explored not only for potential health benefits but also as a potential food preservative. On the other hand, the richness of POPP in antioxidants mainly carried by fibre and its simultaneous richness in unsaturated fatty acids might give rise to additive or synergic effects as gut health benefits, but also lower lipid peroxidation. OP powder biological safety was confirmed, and the powders also demonstrated adequate functional properties for food applications. This study also brings new insight into the research to develop sustainable olive oil production, thus helping to spread the circular bioeconomy in the sector. Further experiments will include incorporation in food matrixes, as well as the validation of biological activity after ingestion.

$\begin{array}{ll}\text { ABBREVIATIONS } \\ \text { OP } & \text { olive pomace } \\ \text { LOPP } & \text { liquid-enriched olive pomace powder } \\ \text { POPP } & \text { pulp-enriched olive pomace powder } \\ \text { DW } & \text { dry weight } \\ \text { DF } & \text { dietary fibre } \\ \text { ADF } & \text { antioxidant dietary fibre } \\ \text { TPC } & \text { total phenolic compounds } \\ \text { FPC } & \text { free phenolics compounds } \\ \text { BPC } & \text { bound phenolics compounds }\end{array}$

$\begin{array}{ll}\text { TDF } & \text { total dietary fibre } \\ \text { IDF } & \text { insoluble dietary fibre } \\ \text { SDF } & \text { soluble dietary fibre } \\ \text { AOX } & \text { antioxidant activity } \\ \text { TE } & \text { Trolox-equivalents } \\ \text { UA } & \text { uronic acids } \\ \text { MIC } & \text { minimum inhibitory concentration } \\ \text { MBC } & \text { minimum bactericidal concentration } \\ \text { WHC } & \text { water-holding capacity } \\ \text { OHC } & \text { oil-holding capacity }\end{array}$

\section{CONFLICT OF INTEREST}

The authors declare that they have no conflict of interest.

\section{ACKNOWLEDGEMENTS}

TBR thanks the Fundação para a Ciência e Tecnologia (FCT), Portugal for PhD grant SFRH/BDE/108271/2015 and the financial support of Association BLC3 - Technology and Innovation Campus. This work was supported by National Funds from FCT - Fundação para a Ciência e a Tecnologia through the project MULTIBIOREFINERY - SAICTPAC/0040/2015 (POCI-01-0145-FEDER-016403). We are also grateful for the scientific collaboration under the FCT project UID/Multi/50016/2019.

\section{AUTHORS' CONTRIBUTIONS}

TBR processed the raw material, performed the analysis and wrote and edited the manuscript. AO designed the antioxidant activity and HPLC method and helped analyse the data. MC performed the Ames test. MV, EMC and SS executed the XTT test and analysed its results. JN and AAV supervised all the work and edited the manuscript. MP edited the manuscript and oversaw the project.

\section{REFERENCES}

1 European Commission. A New Circular Economy Action Plan for a Cleaner and More Competitive Europe [Internet]. (2020) Available: https://www.un.org/sustainabledevelopment/sustainableconsumption-production/ [1 July 2020]

2 European Commission. A Sustainable Bioeconomy for Europe: Strengthening the Connection between Economy, Society and the Environment, Updated Bioeconomy Strategy: COM/2018/673 Final [Internet]. Brussels; (2018). Available: https://ec.europa.eu/research/ bioeconomy/index.cfm?pg=policy\&lib=strategy [31 March 2020]

3 Nunes MA, Pawlowski S, Costa ASG, Alves RC, Oliveira MBPP and Velizarov S, Valorization of olive pomace by a green integrated approach applying sustainable extraction and membrane-assisted concentration. Sci Total Environ 652:40-47 (2019 Feb). Available from: https://linkinghub.elsevier.com/retrieve/pii/S0048969718340956.

4 Dermeche S, Nadour M, Larroche C, Moulti-Mati F and Michaud P, Olive mill wastes: biochemical characterizations and valorization strategies. Process Biochem 48:1532-1552 (2013). https://doi.org/10. 1016/j.procbio.2013.07.010.

5 Rigane G, Bouaziz M, Baccar N, Abidi S, Sayadi S and Ben SR, Recovery of Hydroxytyrosol rich extract from two-phase Chemlali olive pomace by chemical treatment. J Food Sci 77:1077-1083 (2012).

6 Galanakis CM, Olive fruit dietary fiber: components, recovery and applications. Trends Food Sci Technol 22:175-184 (2011 Apr). https://doi.org/10.1016/j.tifs.2010.12.006.

7 Nunes MA, Costa ASG, Bessada S, Santos J, Puga H, Alves RC et al., Olive pomace as a valuable source of bioactive compounds: a study regarding its lipid- and water-soluble components. Sci Total Environ 644: 229-236 (2018 Dec). https://doi.org/10.1016/j.scitotenv.2018.06.350.

8 Rodrigues F, da Mota Nunes MA and MBP PO, Applications of recovered bioactive compounds in cosmetics and health care products, 
in Olive Mill Waste: Recent Advances for Sustainable Management. Elsevier, United Kingdom/United States, pp. 255-274 (2017).

9 Commission Regulation 2008/98/EC. Directive 2008/98/EC of the European Parliament and of the Council of 19 November 2008 on waste and repealing certain directives. (2008).

10 Kasapidou E, Sossidou E and Mitlianga P, Fruit and vegetable coproducts as functional feed ingredients in farm animal nutrition for improved product quality. Agriculture 5:1020-1034 (2015 Oct 21). Available from: http://www.mdpi.com/2077-0472/5/4/1020 [30 June 2020].

11 Galanakis CM, Recovery of high added-value components from food wastes: conventional, emerging technologies and commercialized applications. Trends Food Sci Technol 26:68-87 (2012 Aug). https:// doi.org/10.1016/j.tifs.2012.03.003.

12 Laufenberg G, Kunz B and Nystroem M, Transformation of vegetable waste into value added products: (a) the upgrading concept; (b) practical implementations, in Bioresource Technology, Vol. 87. pp. 167-198 (2003). https://doi.org/10.1016/S0960-8524(02) 00167-0.

13 Coderoni $S$ and Perito MA, Sustainable consumption in the circular economy. An analysis of consumers' purchase intentions for wasteto-value food. J Clean Prod 252:119870 (2020 Apr;). Available from: https://linkinghub.elsevier.com/retrieve/pii/S0959652619347407.

14 Torres-León C, Ramírez-Guzman N, Londoño-Hernandez L, MartinezMedina GA, Díaz-Herrera R, Navarro-Macias $V$ et al., Food waste and byproducts: an opportunity to minimize malnutrition and hunger in developing countries. Front Sustain Food Syst 2:1-17 (2018).

15 García-Lomillo J, ML G-SJ, Del Pino-García R, Rivero-Pérez MD and Muñiz-Rodríguez $\mathrm{P}$, Antioxidant and antimicrobial properties of wine byproducts and their potential uses in the food industry. J Agric Food Chem 62:12595-12602 (2014 Dec 31). Available from: http://pubs.acs.org/doi/abs/10.1021/jf5042678 [11 June 2016].

16 Saura-Calixto F, Antioxidant dietary fiber product: a new concept and a potential food ingredient. J Agric Food Chem 46:4303-4306 (1998 Oct [cited 2016 Jun 11]). https://doi.org/10.1021/jf9803841.

17 EFSA, Scientific opinion on the substantiation of health claims related to polyphenols in olive and protection of LDL particles from oxidative damage (ID 1333, 1638, 1639, 1696, 2865), maintenance of normal blood HDL cholesterol concentrations (ID 1639), mainte. EFSA J 9:2033 (2011 Apr). Available from: http://www.sciencedirect.com/ science/article/B6X0P-475JTJK-4/2/ 3677efe69237475e14c040c2e73f14f2\%5Cnhttp://www. sciencedirect.com/science? ob=ArticleURL\& udi=B6XOP-475JTJK$4 \&$ user $=474718 \&$ _coverDate $=02 / 25 / 2003 \&$ _alid $=1612418182 \&$ $\mathrm{rdoc}=1 \& \mathrm{fmt}=$ high \& orig $=$ searc.

18 Achmon $Y$ and Fishman A, The antioxidant hydroxytyrosol: biotechnological production challenges and opportunities. Appl Microbiol Biotechnol 99:1119-1130 (2014).

19 Pazos M, Alonso A, Sánchez I and Medina I, Hydroxytyrosol prevents oxidative deterioration in foodstuffs rich in fish lipids. J Agric Food Chem 56:3334-3340 (2008 May) Available from: https://pubs.acs. org/doi/10.1021/jf073403s

20 Martínez L, Ros G and Nieto G, Hydroxytyrosol: health benefits and use as functional ingredient in meat. Medicines 5:13 (2018 Jan 23). Available from: http://www.mdpi.com/2305-6320/5/1/13 [19 May 2020].

21 Ouaglia M, Moretti C, Cerri M, Linoci G, Cappelletti G, Urbani S et al, Effect of extracts of wastewater from olive milling in postharvest treatments of pomegranate fruit decay caused by Penicillium adametzioides. Postharvest Biol Technol 118:26-34 (2016). https://doi. org/10.1016/j.postharvbio.2016.03.012.

22 Ahmad-Qasem MH, Barrajon-catalan E, Micol V, Cárcel JA and Garciaperez JV, Influence of air temperature on drying kinetics and antioxidant potential of olive pomace. J Food Eng 119:516-524 (2013). https://doi.org/10.1016/j.jfoodeng.2013.06.027.

23 Uribe E, Lemus-Mondaca R, Vega-Gálvez A, López LA, Pereira K, López J et al., Quality characterization of waste olive cake during hot air drying: nutritional aspects and antioxidant activity. Food Bioprocess Technol 6:1207-1217 (2013).

24 Campos DA, Madureira AR, Sarmento B, Pintado MM and Gomes AM, Technological stability of solid lipid nanoparticles loaded with phenolic compounds: drying process and stability along storage. J Food Eng 196:1-10 (2017 Mar). Available from: https://ac.els-cdn.com/ S0260877416303703/1-s2.0-S0260877416303703-main.pdf?_tid= 4770ebc8-d4f8-11e7-a37e-00000aacb360\&acdnat $=1511955027$ 26980cd4317528738079460955564efd [29 November 2017].

25 Sinrod AJG, Avena-Bustillos RJ, Olson DA, Crawford LM, Wang SC and $\mathrm{TH} \mathrm{MH}$, Phenolics and antioxidant capacity of pitted olive pomace affected by three drying technologies. J Food Sci 84:412-420 (2019).

26 Pérez-Jiménez J, Díaz-Rubio ME and Saura-Calixto F, Obtainment and characterization of a potential functional ingredient from olive. Int J Food Sci Nutr 66:749-754 (2015 Oct 3). Available from: http:// www.tandfonline.com/doi/full/10.3109/09637486.2015.1095863 [8 Aug 2016].

27 Speroni CS, Stiebe J, Guerra DR, Beutinger Bender AB, Ballus CA, dos Santos DR et al., Micronization and granulometric fractionation improve polyphenol content and antioxidant capacity of olive pomace. Ind Crops Prod 137:347-355 (2019 Oct 1). Available from: https://linkinghub.elsevier.com/retrieve/pii/S0926669019303309 [21 May 2020].

28 Ying DY, Hlaing MM, Lerisson J, Pitts K, Cheng L, Sanguansri L et al., Physical properties and FTIR analysis of rice-oat flour and maize-oat flour based extruded food products containing olive pomace. Food Res Int 100:665-673 (2017). https://doi.org/10.1016/j.foodres.2017.07.062.

29 Conterno L, Martinelli F, Tamburini M, Fava F, Mancini A, Sordo M et al., Measuring the impact of olive pomace enriched biscuits on the gut microbiota and its metabolic activity in mildly hypercholesterolaemic subjects. Eur J Nutr 58:63-81 (2019 Feb 9). Available from: https://link.springer.com/content/pdf/10.1007\%2Fs00394-017-15722.pdf [20 December 2018]

30 Uribe E, Pasten A, Lemus-Mondaca R, Vega-Gálvez A, Quispe-Fuentes I, Ortiz J et al., Comparison of chemical composition, bioactive compounds and antioxidant activity of three olive-waste cakes. $J$ Food Biochem 39:189-198 (2015 Apr). Available from: http://doi.wiley. com/10.1111/jfbc.12120 [11 June 2016].

31 Pukalskienè $M$, Slapšytė G, Dedonytè V, Lazutka JR, Mierauskienė J and Venskutonis PR, Genotoxicity and antioxidant activity of five Agrimonia and Filipendula species plant extracts evaluated by comet and micronucleus assays in human lymphocytes and Ames salmonella/microsome test. Food Chem Toxicol 113:303-313 (2018 Mar) Available from: https://linkinghub.elsevier.com/retrieve/pii/ S0278691517307731 [2 Apr 2019].

32 Martínez R, Torres P, Meneses MA, Figueroa JG, Pérez-Álvarez JA and Viuda-Martos $M$, Chemical, technological and in vitro antioxidant properties of mango, guava, pineapple and passion fruit dietary fibre concentrate. Food Chem 135:1520-1526 (2012 Dec). Available from: https://doi.org/10.1016/j.foodchem.2012.05.057 [26 Aug 2018].

33 AOAC. AOAC Official Methods of Analysis (1990).

34 Deng $\mathrm{Q}$, Penner $\mathrm{MH}$ and Zhao Y, Chemical composition of dietary fiber and polyphenols of five different varieties of wine grape pomace skins. Food Res Int 44:2712-2720 (2011 Nov). Available from: https://linkinghub.elsevier.com/retrieve/pii/S0963996911003425.

35 Amorim M, Pereira JO, Gomes D, Pereira CD, Pinheiro H and Pintado M, Nutritional ingredients from spent brewer's yeast obtained by hydrolysis and selective membrane filtration integrated in a pilot process. J Food Eng 185:42-47 (2016 Sep). Available from: https:// linkinghub.elsevier.com/retrieve/pii/S0260877416301157.

36 Pimentel LL, Fontes AL, Gomes AM and Rodríguez-Alcalá LM, Considerations about the in situ derivatization and fractionation of EFA and NEFA in biological and food samples. Methods X 2:475-484 (2015).

37 Xie P-J, Huang L-X, Zhang C and Zhang Y-L, Phenolic compositions, and antioxidant performance of olive leaf and fruit (Olea europaea L.) extracts and their structure-activity relationships. J Funct Foods 16:460-471 (2015 Jun). Available from: https://linkinghub.elsevier. com/retrieve/pii/S1756464615002418 [7 July 2016].

38 Oliveira A, Alexandre EMC, Coelho M, Barros RM, Almeida DPF and Pintado M, Peach polyphenol and carotenoid content as affected by frozen storage and pasteurization. LWT Food Sci Technol 66 361-368 (2016). https://doi.org/10.1016/j.lwt.2015.10.037.

39 Guo W and Beta T, Phenolic acid composition and antioxidant potential of insoluble and soluble dietary fibre extracts derived from select wholegrain cereals. Food Res Int 51:518-525 (2013 May). Available from: http://linkinghub.elsevier.com/retrieve/pii/S0963996913000276.

40 Monforte AR, Martins SIFS and Silva Ferreira AC, Strecker aldehyde formation in wine: new insights into the role of gallic acid, glucose, and metals in phenylacetaldehyde formation. J Agric Food Chem 66 2459-2466 (2018 Mar 14). Available from: https://pubs.acs.org/ sharingguidelines [2 Apr 2019]. 
41 Lozano-Sánchez J, Bendini A, Quirantes-Piné R, Cerretani L, SeguraCarretero $A$ and Fernández-Gutiérrez A, Monitoring the bioactive compounds status of extra-virgin olive oil and storage by-products over the shelf life. Food Contro/ 30:606-615 (2013 Apr). Available from: https://linkinghub.elsevier.com/retrieve/pii/S0956713512003684.

42 Jerman Klen T and Mozetič Vodopivec B, The fate of olive fruit phenols during commercial olive oil processing: traditional press versus continuous two- and three-phase centrifuge. LWT Food Sci Technol 49: 267-274 (2012 Dec). Available from: http://linkinghub.elsevier. com/retrieve/pii/S0023643812001910 [11 June 2016].

43 Oliveira CM, Barros AS, Silva Ferreira AC and AMS S, Influence of the temperature and oxygen exposure in red port wine: a kinetic approach. Food Res Int 75:337-347 (2015 Sep). https://doi.org/10. 1016/j.foodres.2015.06.024.

44 Alexandre EMC, Silva S, Santos SAO, Silvestre AJD, Duarte MF, Saraiva JA et al., Antimicrobial activity of pomegranate peel extracts performed by high pressure and enzymatic assisted extraction. Food Res Int 115:167-176 (2019 Jan). Available from: https://linkinghub. elsevier.com/retrieve/pii/S096399691830680X [27 March 2019].

45 Cano A, Acosta M and Arnao MB, A method to measure antioxidant activity in organic media: application to lipophilic vitamins. Redox Rep 5:365-370 (2000). Available from: http://www.tandfonline. com/doi/full/10.1179/135100000101535933.

46 Oliveira A and Pintado M, Stability of polyphenols and carotenoids in strawberry and peach yoghurt throughout in vitro gastrointestinal digestion. Food Funct 6:1611-1619 (2015). Available from: http:// xlink.rsc.org/?DOI=C5FO00198F [22 Aug 2018].

47 Madureira AR, Campos DA, Fonte P, Nunes S, Reis F, Gomes AM et al., Characterization of solid lipid nanoparticles produced with carnauba wax for rosmarinic acid oral delivery. RSC Adv 5: 22665-22673 (2015). Available from: http://xlink.rsc.org/?DOI= C4RA15802D [14 June 2016].

48 Fernandes JC, Tavaria FK, Soares JC, Ramos ÓS, João Monteiro M, Pintado ME et al., Antimicrobial effects of chitosans and chitooligosaccharides, upon Staphylococcus aureus and Escherichia coli, in food model systems. Food Microbiol 25:922-928 (2008 Oct). Available from: www.elsevier.com/locate/fm [8 Apr 2019].

49 Cano-Chauca M, Stringheta PC, Ramos AM and Cal-Vidal J, Effect of the carriers on the microstructure of mango powder obtained by spray drying and its functional characterization. Innov Food Sci Emerg Technol 6:420-428 (2005 Dec). Available from: www.elsevier.com/ locate/ifset [21 Aug 2018].

50 Rubio-Senent $F$, Rodríguez-Gutiérrez G, Lama-Muñoz $A$ and Fernández-Bolaños J, Pectin extracted from thermally treated olive oil by-products: characterization, physico-chemical properties, in vitro bile acid and glucose binding. Food Hydrocolloids 43: 311-321 (2015). Available from: http://www.sciencedirect.com/ science/article/pii/S0268005X14002276 [11 June 2016].

51 Costa JR, Amorim M, Vilas-Boas A, Tonon RV, Cabral LMC, Pastrana L et al., Impact of in vitro gastrointestinal digestion on the chemical composition, bioactive properties, and cytotoxicity of Vitis vinifera L. Cv. Syrah grape pomace extract. Food Funct 10:1856-1869 (2019). Available from: http://xlink.rsc.org/?DOI=C8FO02534G [9 Apr 2019].

52 Maron DM and Ames BN, Revised methods for the salmonella mutagenicity test. Mutat Res Mutagen Relat Subj 113:173-215 (1983 Mar 1). Available from: https://www.sciencedirect.com/science/article/pii/ 0165116183900109?via\%3Dihub [16 February 2019].

53 EFSA, Scientific opinion on the substantiation of health claims related to potassium and maintenance of normal muscular and neurological function (ID 320, 386) and maintenance of normal blood pressure (ID 321) pursuant to article 13(1) of regulation (EC) no. 192. EFSA J 8:1-17 (2010 Feb). Available from: http://doi.wiley.com/10. 2903/j.efsa.2010.1469.

54 Ghoreishi SM and Shahrestani RG, Subcritical water extraction of mannitol from olive leaves. J Food Eng 93:474-481 (2009 Aug). Available from: http://linkinghub.elsevier.com/retrieve/pii/S0260877409000909 [25 Nov 2017].

55 Aquilina G, Bampidis V, De M, Bastos L, Guido Costa L, Flachowsky G et al., Scientific opinion on the safety and efficacy of formic acid when used as a technological additive for all animal species. EFSA J 12:16 (2014). Available from: https://efsa.onlinelibrary.wiley.com/ doi/pdf/10.2903/j.efsa.2014.3827 [27 Aug 2018].

56 Park J-N, Fukumoto Y, Fujita E, Tanaka T, Washio T, Otsuka S et al., Chemical composition of fish sauces produced in southeast and east
Asian countries. J Food Compos Anal 14:113-125 (2001 Apr). Available from: http://linkinghub.elsevier.com/retrieve/pii/ S0889157500909633 [11 February 2019].

57 Crizel T d M, Hermes VS, de Oliveira Rios A and Flôres SH, Evaluation of bioactive compounds, chemical and technological properties of fruits byproducts powder. J Food Sci Technol 53:4067-4075 (2016 Nov 5). Available from: https://link.springer.com/content/pdf/10. 1007\%2Fs13197-016-2413-7.pdf [21 August 2017].

58 Prandi B, Faccini A, Lambertini $F$, Bencivenni $M$, Jorba $M$, Van Droogenbroek $B$ et al., Food wastes from agrifood industry as possible sources of proteins: a detailed molecular view on the composition of the nitrogen fraction, amino acid profile and racemisation degree of 39 food waste streams. Food Chem 286:567-575 (2019 Jul). Available from: https://linkinghub.elsevier.com/retrieve/pii/ S0308814619302456 [11 February 2019].

59 Schutyser MAl, Pelgrom PJM, van der Goot AJ and Boom RM, Dry fractionation for sustainable production of functional legume protein concentrates. Trends Food Sci Technol 45:327-335 (2015). https:// doi.org/10.1016/j.tifs.2015.04.013.

60 Lopez-Huertas E, Health effects of oleic acid and long chain omega-3 fatty acids (EPA and DHA) enriched milks. A review of intervention studies. Pharmacol Res 61:200-207 (2010 Mar). Available from: https://linkinghub.elsevier.com/retrieve/pii/S1043661809002680 [9 February 2019].

61 Mujico JR, Baccan GC, Gheorghe A, Díaz LE and Marcos A, Changes in gut microbiota due to supplemented fatty acids in diet-induced obese mice. Br J Nutr 110:711-720 (2013 Aug 28). Available from: https://doi.org/10.1017/S0007114512005612 [11 February 2019].

62 Saura-Calixto F, Dietary fiber as a carrier of dietary antioxidants: an essential physiological function. J Agric Food Chem 59:43-49 (2011 Jan 12). Available from: https://pubs.acs.org/doi/10.1021/jf1036596.

63 Goñi I, Díaz-Rubio ME, Pérez-Jiménez J and Saura-Calixto F, Towards an updated methodology for measurement of dietary fiber, including associated polyphenols, in food and beverages. Food Res Int 42: 840-846 (2009). https://doi.org/10.1016/j.foodres.2009.03.010.

64 Gullón B, Gómez B, Martínez-Sabajanes M, Yáñez R, Parajó JC and Alonso JL, Pectic oligosaccharides: manufacture and functional properties. Trends Food Sci Technol 30:153-161 (2013 Apr 1). Available from: https://www.sciencedirect.com/science/article/pii/ S0924224413000149 [14 February 2019].

65 Chen Z, Li S, Fu Y, Li C, Chen D and Chen H, Arabinoxylan structural characteristics, interaction with gut microbiota and potential health functions. J Funct Foods 54:536-551 (2019 Mar). Available from: https://linkinghub.elsevier.com/retrieve/pii/S1756464619300696 [13 February 2019].

66 Sato Y, Itagaki S, Kurokawa T, Ogura J, Kobayashi M, Hirano T et al., In vitro and in vivo antioxidant properties of chlorogenic acid and caffeic acid. Int J Pharm 403:136-138 (2011 Jan). Available from: https:// ac.els-cdn.com/S0378517310007556/1-s2.0-S0378517310007556main.pdf? tid=fabd629a-ced3-11e7-a8c8-00000aacb35f\&acdnat= 1511279730_74baa0781a5f0067220c02941250e152 [21 November 2017].

67 Jakobek L, Interactions of polyphenols with carbohydrates, lipids and proteins. Food Chem 175:556-567 (2015 May). https://doi.org/10. 1016/j.foodchem.2014.12.013.

68 Ozdal T, Yalcinkaya İE, Toydemir G and Capanoglu E, Polyphenolprotein interactions and changes in functional properties and digestibility, in Encyclopedia of Food Chemistry. Elsevier, Netherlhands, United Kingdom and United States, pp. 566-577 (2019). Available from: https://linkinghub.elsevier.com/retrieve/pii/ B978008100596521490X [15 February 2019].

69 Gorelik S, Kanner J, Schurr D and Kohen R, A rational approach to prevent postprandial modification of LDL by dietary polyphenols. J Funct Foods 5:163-169 (2013 Jan). Available from: https://doi.org/ 10.1016/j.jf.2012.09.008 [14 February 2019].

70 Romero C, Brenes M, García P and Garrido A, Hydroxytyrosol 4- $\beta$ D-glucoside, an important phenolic compound in olive fruits and derived products. J Agric Food Chem 50:3835-3839 (2002 Jun). Available from: https://pubs.acs.org/sharingguidelines [14 February 2019].

71 Nieto Calvache J, Cueto M, Farroni A, de Escalada Pla $M$ and Gerschenson LN, Antioxidant characterization of new dietary fiber concentrates from papaya pulp and peel (Carica papaya L.). J Funct Foods 27:319-328 (2016 Dec). Available from: https://linkinghub. elsevier.com/retrieve/pii/S1756464616302882 [10 November 2016]. 
72 Uribe E, Lemus-Mondaca R, Vega-Gálvez A, Zamorano M, QuispeFuentes I, Pasten A et al., Influence of process temperature on drying kinetics, physicochemical properties and antioxidant capacity of the olive-waste cake. Food Chem 147:170-176 (2014 Mar). https://doi. org/10.1016/j.foodchem.2013.09.121.

73 Arnao MB, Some methodological problems in the determination of antioxidant activity using chromogen radicals: a practical case. Trends Food Sci Technol 11:419-421 (2000 Nov). Available from: https://linkinghub.elsevier.com/retrieve/pii/S0924224401000279.

74 Cedola A, Cardinali A, D'Antuono I, Conte A and Del Nobile MA, Cereal foods fortified with by-products from the olive oil industry. Food Biosci 33:100490 (2020 Feb 1). Available from: https://linkinghub. elsevier.com/retrieve/pii/S2212429218305078 [8 Jan 2020].

75 Zhao G, Zhang R, Dong L, Huang F, Tang X, Wei Z et al., Particle size of insoluble dietary fiber from rice bran affects its phenolic profile, bioaccessibility and functional properties. LWT Food Sci Technol 87: 450-456 (2018). https://doi.org/10.1016/j.Iwt.2017.09.016.

76 Obied HK, Bedgood DR, Prenzler PD and Robards K, Bioscreening of Australian olive mill waste extracts: biophenol content, antioxidant, antimicrobial and molluscicidal activities. Food Chem Toxicol $\mathbf{4 5}$ 1238-1248 (2007 Jul). Available from: http://linkinghub.elsevier. com/retrieve/pii/S0278691507000221 [11 June 2016.

77 López-Vargas JH, Fernández-López J, Pérez-Álvarez JA and ViudaMartos M, Chemical, physico-chemical, technological, antibacterial and antioxidant properties of dietary fiber powder obtained from yellow passion fruit (Passiflora edulis var. flavicarpa) co-products. Food Res Int 51:756-763 (2013 May). Available from: https://doi. org/10.1016/j.foodres.2013.01.055 [27 August 2018].

78 Niu Y, Li N, Xia Q, Hou Y and Xu G, Comparisons of three modifications on structural, rheological and functional properties of soluble dietary fibers from tomato peels. LWT Food Sci Technol 88:56-63 (2018 Feb). Available from: http://linkinghub.elsevier.com/retrieve/ $\mathrm{pii} / \mathrm{S} 0023643817307260$

79 Jiang W, Akagi T, Suzuki H, Takimoto A and Nagai H, A new diatom growth inhibition assay using the XTT colorimetric method. Comp Biochem Physiol C 185-186:13-19 (2016 July 1). Available from: https://www.sciencedirect.com/science/article/pii/ S1532045616300205\#bb0260 [16 February 2019]. 